\title{
Nerve injury induced by vibration: prevention of the effect of a conditioning lesion by D600, a $\mathrm{Ca}^{2+}$ channel blocker
}

\author{
A Widerberg, S Bergman, N Danielsen, G Lundborg, L B Dahlin
}

\begin{abstract}
Objectives-Exposing a hind leg of a rat to vibration induces an injury to the sciatic nerve-a so called conditioning lesion. After such injury induced by vibration the regenerative capacity of the nerve is improved and can be detected as an increased axonal outgrowth from a test crush lesion to the same nerve. The purpose was to study whether the effect of a conditioning lesion induced by vibration can be prevented by local treatment with a $\mathrm{Ca}^{2+}$ channel blocker $\mathrm{D} 600$.
\end{abstract}

Methods-D600 (methoxyverapamil) or Ringer's solution was locally applied to the sciatic nerve on one side through a silicone tube connected to a miniosmotic pump, which was implanted subcutaneously. During the same period the hind leg was exposed to vibration $(80 \mathrm{~Hz}$; $32 \mathrm{~m} / \mathrm{s}^{2}$ root mean squared) for five hours daily for five consecutive days. The other hind leg was not vibrated. After the end of exposure to vibration the sciatic nerves were crushed bilaterally (test crush lesions) and three or six days later the regeneration distances of sensory axons were measured by the pinch reflex test.

Results-Nerves in the control animals (without implanted miniosmotic pumps and nerves on to which Ringer's solution was locally applied) that were exposed to vibration showed a significantly increased outgrowth length of sensory axons from the test crush lesion compared with the non-vibrated side. Such an effect of a conditioning lesion from the exposure to vibration was suppressed by local application of $\mathrm{D600}$.

Conclusions-Local administration of a $\mathrm{Ca}^{2+}$ channel blocker $\mathrm{D600}$ can prevent the effect of a conditioning lesion-that is, the nerve injury induced by vibration can be inhibited by D600. This may have implications for the treatment of patients with neuropathy of the hand induced by vibration.

(Occup Environ Med 1997;54:312-315)

Surgery, University

Hospital, Lund

University, Malmö

A Widerberg

$S$ Bergman

N Danielsen

$G$ Lundborg

L B Dahlin

Correspondence to: Dr Lars B Dahlin,
Department of Hand Separtment of Hand S-205 02 Malmö, Sweden.

Accepted 18 December 1996
We have previously shown that axonal outgrowth in the rat sciatic nerve after a test crush lesion is increased when the same hind leg had previously been exposed to vibration of a defined acceleration, frequency, and duration that produced a conditioning lesion. ${ }^{12}$ It has been suggested that such an improved outgrowth of axons can be explained by local changes occurring in the nerve trunk or even changes in the neuron itself. ${ }^{2}$ Such an effect of a conditioning lesion is probably an expression of a harmful nerve injury and might explain the clinical symptoms occurring in patients exposed to vibration. It has been suggested that these symptoms, like vibration induced white finger (VWF), may have a neurological pathophysiological component. ${ }^{34}$ Neurological symptoms can also occur without other symptoms in patients exposed to vibration..$^{4-9}$ The therapeutic possibilities for these patients are limited, but various pharmacological treatments such as the use of $\mathrm{Ca}^{2+}$ channel blockers have been suggested. ${ }^{10-12}$ Theoretically, a $\mathrm{Ca}^{2+}$ channel blocker might attenuate the cellular damage after a neuronal injury. ${ }^{1314}$ Experimentally, local treatment with such a $\mathrm{Ca}^{2+}$ channel blocker (D600; methoxyverapamil) can block the effect of the conditioning lesion resulting from exposure to magnetic fields. ${ }^{15}$ In the present study, we investigated if this substance, which interferes with the entry of calcium through the channels in the cell membrane, can also alter the effect of the conditioning lesion induced by exposure to vibration expressed as stimulation of nerve regeneration.

\section{Materials and methods}

ANIMALS AND $\mathrm{Ca}^{2+}$ CHANNEL BLOCKER

Female Wistar rats $(\mathrm{n}=70)$ weighing 180-200 $\mathrm{g}$ were used. The study was approved by the local ethics committee of Lund University. The rats were anaesthetised by an intraperitoneal injection of a mixture of pentobarbitone $(60 \mathrm{mg} / \mathrm{ml})$ and saline in the proportion $1 / 10$ by volume. One of the sciatic nerves was exposed in the thigh region under sterile conditions. D600 (methoxyverapamil; Sigma) was given locally to the nerve through a miniosmotic pump (2002, $0.5 \mu \mathrm{l} / \mathrm{h}$, Alzet, USA) which was implanted subcutaneously in the back of the rat. A $6 \mathrm{~cm}$ long silicone catheter with an inner diameter of $0.7 \mathrm{~mm}$ (4 FR Mentor Corporation, Goleta, CA) was pulled subcutaneously from the pump to the sciatic nerve in the midthigh region. The distal part of the catheter was perforated and sutured by two single 9-0 Ethilon stitches to the epineurium (figure). The pump and the catheter were filled with Ringer's solution (in $\mathrm{mM}: \mathrm{NaCl} 139 ; \mathrm{KCl} 2 \cdot 4 ; \mathrm{CaCl}_{2} 1 \cdot 4 ; \mathrm{MgSO}_{4}$ 
$2 \cdot 0 ; \mathrm{NaH}_{2} \mathrm{PO}_{4} 0 \cdot 6 ; \mathrm{Na}_{2} \mathrm{HPO}_{4} 3 \cdot 25 ; \mathrm{pH} 7 \cdot 4$ ) only or with Ringer's solution containing D600 at a concentration of $0.2 \mathrm{mg} / \mathrm{ml}$. The wounds were sutured and the animals allowed to recover. The miniosmotic pumps were filled under sterile conditions and pre-activated before implantation with connected silicone tubing in sterile saline $\left(37^{\circ} \mathrm{C}\right)$ according to the recommendations of the manufacturer. The method has previously been described by Rusovan and Kanje. ${ }^{15}$ In their original work the concentration of D600 was $0.1 \mathrm{mg} / \mathrm{ml}$ and the pump delivery rate was $1.0 \mu \mathrm{l} / \mathrm{h}$. As our experimental protocol demanded an administration time $>7$ days we used miniosmotic pumps with a longer delivery time but a lower pumping rate $(0.5 \mu \mathrm{l} / \mathrm{h})$ and a doubled concentration $(0.2 \mathrm{mg} / \mathrm{ml})$, thus giving the same dose to the nerve as described previously.

\section{EXPOSURE TO VIBRATION}

Three days later the rats were reanaesthetised before vibration by an intraperitoneal injection of $0.2 \mathrm{ml}$ of a mixture of pentobarbitone $(60 \mathrm{mg} / \mathrm{ml})$, diazepam $(5 \mathrm{mg} / \mathrm{ml})$, and saline in the proportions $1: 2: 1$ by volume. Animals were placed in a soft network support and the hind paws, to which Ringer's solution with or without D600 was applied to the sciatic nerve, were attached horizontally to a plate which was fixated on the top of a vibration exciter. By this method the hind leg of the rat could be

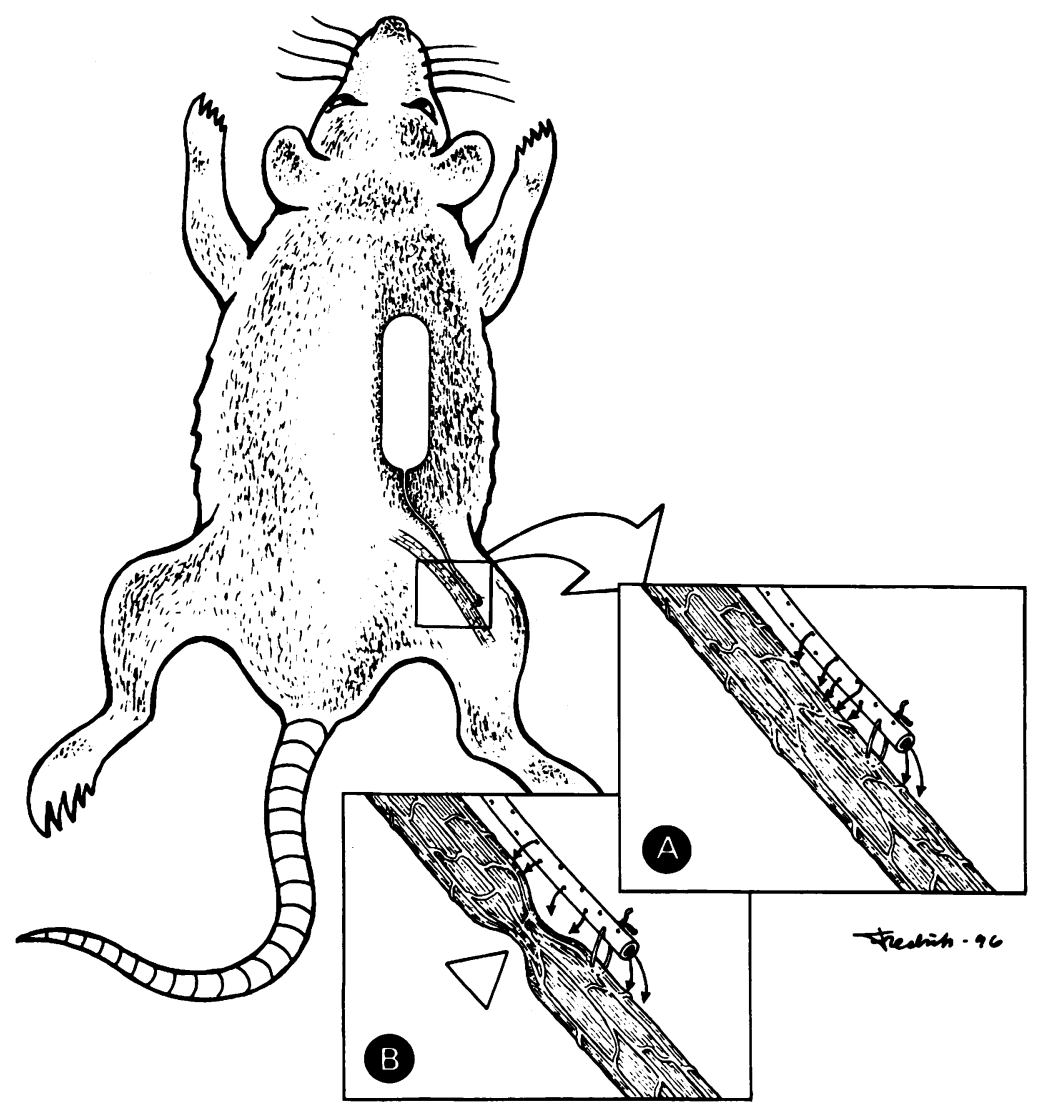

Schematic drawing of the experimental procedure. A miniosmotic pump was implanted subcutaneously in the back and Ringer's solution or D600 + Ringer's solution was locally applied to the sciatic nerve through a silicone catheter $(A)$. The corresponding hind leg was exposed to vibration of defined acceleration, frequency, and duration for five days. Directly after exposure to vibration on the fifth day a test crush lesion was applied to the sciatic nerves bilaterally $(B)$ and the regeneration distances of the sensory nerve fibres were evaluated three or six days later. exposed to sinusoidal vibration for five hours daily for five consecutive days $\left(80 \mathrm{~Hz} ; 32 \mathrm{~m} / \mathrm{s}^{2}\right.$ root mean squared; displacement $127 \mu \mathrm{m}$ root mean squared) according to previous reports, ${ }^{1}$ and the other hind leg served as a non-vibrated control.

EVALUATION OF REGENERATION DISTANCES

Directly after vibration on the fifth day, the sciatic nerves on both sides were exposed, crushed with special pliers, and a 90 Ethilon suture was attached to the epineurium at the site of the crush. After three or six days the rats were reanaesthetised and the sciatic nerves were again exposed. The regeneration distance was measured by the pinch reflex test. ${ }^{16-18}$ Briefly, the peroneal and tibial branches of the sciatic nerve were cut as distally as possible and consecutively pinched by forceps. When the tips of the fastest growing sensory nerve fibres were pinched the back leg showed a slight reflex movement and the distance between that point and the suture marked crush site was referred to as the regeneration distance. Several previous studies have shown that the pinch reflex test is an accurate method to evaluate regeneration distances as it corresponds to the distance measured by immunostaining of neurofilaments. ${ }^{17-19}$ After the pinch reflex test the animals were killed and the miniosmotic pumps were taken out and opened to confirm that they had been working throughout the experiment.

In control experiments, rats without implanted miniosmotic pumps were vibrated in the same way for five hours daily for five consecutive days and the sciatic nerve was crushed bilaterally on the fifth day of vibration. Evaluation of the regeneration distance by the pinch reflex test was done after three or six days.

\section{STATISTICS}

The results are presented as median (interquartile range (IQR)). The Wilcoxon signed rank test was used to compare the data within the same rat (paired data). The Kruskal-Wallis test including multiple comparisons between different treatments ${ }^{20}$ was used to compare the different experimental groups at three or six days. A P value $\leqslant 0.05$ was accepted as significant. The calculations were done on a Macintosh computer equipped with StatView 4.02; FPU version.

\section{Results}

The table shows the results. Paired comparisons showed that in the control animals the leg exposed to vibration (no miniosmotic pumps) had significantly longer regeneration distances after both three and six days of regeneration $(P=0.045$ and $P=0.049$, respectively). In animals treated only with Ringer's solution the regeneration distances were also significantly increased on the leg exposed to vibration after three and six days of regeneration (paired comparison; $P=0.046$ and $0 \cdot 019$, respectively). Application of D600 + Ringer's solution, however, abolished the 
Effects of exposure to vibration ( $80 \mathrm{~Hz}, 32 \mathrm{~m} / \mathrm{s}^{2} \mathrm{rms} ; 5$ hours daily for 5 days) and local administration of the $\mathrm{Ca}^{2+}$ channel blocker $\mathrm{D} 600$ on nerve regeneration after a nerve crush of the rat sciatic nerve

\begin{tabular}{|c|c|c|c|c|c|c|}
\hline & \multicolumn{6}{|c|}{ Regeneration distances (median mm (IQR)) } \\
\hline & \multicolumn{3}{|l|}{ Three days } & \multicolumn{3}{|l|}{ Six days } \\
\hline & $\begin{array}{l}\text { Non-vibrated } \\
\text { leg }\end{array}$ & $\begin{array}{l}\text { Vibrated } \\
\text { leg }\end{array}$ & Pvalue ${ }^{\star}$ & $\begin{array}{l}\text { Non-vibrated } \\
\text { leg }\end{array}$ & $\begin{array}{l}\text { Vibrated } \\
\text { leg }\end{array}$ & Pvalue ${ }^{\star}$ \\
\hline$\underset{n}{\text { Control }}$ & ${ }_{12}^{5 \cdot 0(0.8) \dagger}$ & $12^{6 \cdot 1(1 \cdot 0)}$ & 0.045 & $\begin{array}{l}15 \cdot 6(1 \cdot 6) \\
8\end{array}$ & $\begin{array}{c}16 \cdot 5(1 \cdot 3) \\
8\end{array}$ & 0.049 \\
\hline $\begin{array}{l}\text { Ringer's } \\
\text { solution } \\
\text { n }\end{array}$ & ${ }_{14}^{5 \cdot 4(1 \cdot 4)}$ & ${ }_{14}^{6 \cdot 3(2 \cdot 1)}$ & 0.046 & $\begin{array}{l}16 \cdot 1(3 \cdot 8) \\
13\end{array}$ & $\begin{array}{l}17 \cdot 5(3 \cdot 3) \ddagger \\
13\end{array}$ & $0 \cdot 019$ \\
\hline $\begin{array}{l}\text { D-600 } \\
\text { + Ringer's } \\
\text { solution } \\
\quad n\end{array}$ & $\begin{array}{l}6 \cdot 4(2 \cdot 2) \\
11\end{array}$ & $1_{11}^{5 \cdot 5(2 \cdot 0)}$ & $0 \cdot 13$ & $\begin{array}{l}16 \cdot 1(2 \cdot 3) \\
12\end{array}$ & $\begin{array}{l}14 \cdot 8(2 \cdot 0) \\
12\end{array}$ & $0 \cdot 071$ \\
\hline
\end{tabular}

ॠWilcoxon signed rank test for paired data.

$+\mathrm{P}=0.040 v \mathrm{D} 600+$ Ringer solution, Kruskal-Wallis test.

$\pm \mathrm{P}=0.027 v \mathrm{D} 600+$ Ringer solution, Kruskal-Wallis test.

stimulatory effect of the exposure to vibration. In these experiments, in which D600 + Ringer's solution was applied to one leg, the regeneration distances after three and six days had a tendency (paired comparisons), although not significant $(P=0.13$ and 0.07 respectively), to be even shorter in the leg exposed to vibration compared with the hind leg not exposed to vibration.

The Kruskal-Wallis test showed that there were significantly shorter regeneration distances in nerves exposed to vibration treated with D600 + Ringer's solution than in nerves treated only with Ringer's solution at six days $(P=0.027)$. In the D600 + Ringer's solution series non-vibrated nerves had significantly longer regeneration distances at three days than non-vibrated control nerves $(P=0.040)$. The Kruskal-Wallis test did not show any significant difference between non-exposed nerves at six days $(P=0.64)$ or between nerves exposed to vibration at three days $(P=$ $0 \cdot 58)$.

\section{Discussion}

The present study showed that a $\mathrm{Ca}^{2+}$ channel blocker (D600), which is known to block the influx of $\mathrm{Ca}^{2+}$ through voltage sensitive calcium channels, ${ }^{21}{ }^{22}$ can abolish the effect of the conditioning lesion in peripheral nerves, which is induced by exposing the hind leg of a rat to vibration. A similar phenomenon has been found in rats exposed to $50 \mathrm{~Hz}$ sinusoidal magnetic fields. ${ }^{15}$ The present study also further confirmed the fact that exposure to vibration can induce the effect of a conditioning lesion, which is an increased regenerative capacity of the nerve from an initial traumafor example, exposure to vibration-and which is detected as an increased axonal outgrowth from a second test crush lesion. The phenomenon of a conditioning lesion is considered to be a sign of nerve injury. ${ }^{1223}$ To study whether the application of the miniosmotic pump and the small silicone tube used to locally apply the drug to the nerve influenced the regenerating axons, experiments were performed in which the miniosmotic pumps were loaded only with Ringer's solution. In these experiments an effect of the conditioning lesion was still found on the vibrated leg three and six days after exposure to vibration as in previous experiments without pumps. Thus we conclude that the application of Ringer's solution to the nerve in itself did not affect the regenerating axons.

A surprising finding was that the regeneration distances were longer in the nerves in the leg not exposed to vibration (table, $\mathbf{P}=$ 0.040), when treated with D600 + Ringer's solution, than in the corresponding nerves in controls. Such an effect has not previously been found in studies in which regeneration distances were investigated in rats exposed to exogenous magnetic fields and treated with D600. ${ }^{15}$ It may be explained by the fact that a low concentration of $\mathrm{Ca}^{2+}$ channel blocker can accelerate axonal sprouting in healthy nerves not injured by exposure to vibration. This has been found in previous studies. ${ }^{24} 25$ This phenomenon also implies that there may be a systemic effect of D600 at the level of the nerve cell body, which may even work on the vibrated leg, partly explaining the neuroprotective effect.

We have suggested that exposure to vibration causes injury to the peripheral nerve as vibration can act by causing a conditioning lesion, which is probably a sign of nerve injury. ${ }^{1}$ Local application of the calcium channel blocker D600 to the nerve abolished the effect of the conditioning lesion when paired comparison was made and there was even a significantly ( $P=0.027)$ shorter regeneration distance at the vibrated side at six days compared with nerves treated with only Ringer's solution. This indicates that, due to the action of the $\mathrm{Ca}^{2+}$ channel blocker, the initial trauma to the nerve (exposure to vibration) does not induce any injury which can be detected by the second test crush lesion. The abolishing effect of D600 indicates that the drug has a neuroprotective effect on neuronal injury induced by vibration. Such an effect is not only related to exposure to vibration, but also to another technique for inducing conditioning lesions-namely, magnetic fields. ${ }^{15} 19$ The mechanisms behind this neuroprotective effect in our study are not known but the $\mathrm{Ca}^{2+}$ channel blocker D600 stops the influx of $\mathrm{Ca}^{2+}$ through voltage sensitive calcium channels. ${ }^{21} 22$ Therefore, it can prevent the activation of proteases dependent on $\mathrm{Ca}^{2+}$ and generation of free radicals which have a toxic action on axons and thereby the drug can have a neuroprotective effect on the neurons exposed to vibration. ${ }^{131426}$

The hand-arm vibration syndrome represents a considerable clinical problem usually dominated by neurological and vasospastic symptoms. ${ }^{4}$ There are limited possibilities for medical treatment of patients with hand-arm vibration syndrome. Blocking of $\mathrm{Ca}^{2+}$ channels has been used for the treatment of primary Raynaud's phenomenon as well as Raynaud's phenomenon induced by VWF. Such treatment has been reported to be mostly effective, ${ }^{1011}$ and is recommended. ${ }^{12}$ However, many patients have neurological symptoms alone or in combination with vasospastic symptoms. The present study indicates that 
$\mathrm{Ca}^{2+}$ channel blockers have a potential clinical value for treatment not only of vasospastic symptoms, but also of neuropathy of the hand induced by vibration. Good relief of such symptoms has also been found in symptomatic stone workers treated with $\mathrm{Ca}^{2++}$ channel blockers in Sweden (G Wemmenborn; personal communication).

The study was supported by grants from the Swedish Council for Work Life Research and the Medical Research Council (5188). We thank Lena Stenberg for technical assistance and Associate Professor Björn Holmquist, Department of Mathematical Statistics for advice on the statistical analysis and Associate Professor Martin Kanje for valuable discussions.

1 Dahlin LB, Necking LE, Lundström R, Lundborg G. Vibration exposure and conditioning lesion effect in nerves. An experimental study in rats. 7 Hand Surg $[\mathrm{Am}]$ 1992;17:858-61.

2 Bergman S, Widerberg A, Danielsen N, Lundborg G, Dahlin LB. Nerve regeneration in nerve grafts conditioned by vibration exposure. Restorative Neurology and tioned by vibration exposure

3 Ekenvall L, Lindblad LE. Is vibration white finger a primary sympathetic injury? $\mathrm{Br} \mathcal{F}$ Ind Med 1986;43:702-6.

4 Strömberg T, Dahlin LB, Lundborg G. Hand problems among one hundred vibration-exposed symptomatic male workers. f Hand Surg $[B r]$ 1996;21:315-9.

5 Brammer AJ, Piercy JE, Auger PL, Nohara S. Tactile perception in hands occupationally exposed to vibration. $f$ Hand Surg [Am] 1987;12:870-5.

6 Brammer AJ, Piercy JE, Auger PL. Assessment of impaired tactile sensation: a pilot study. Scand $\mathcal{F}$ Work Environ Health 1987;13:380-4.

7 Färkkilä M, Aatola S, Starck J, Pyykkö I, Korhonen O. Vibration-induced neuropathy among forestry workers. Vibration-induced neuropathy amol Scand 1985;71:221-5.
Acta Neuro

8 Hjortsberg U, Rosén I, Örbaek P, Lundborg G, Balogh I. Finger receptor dysfunction in dental technician exposed to high frequency of vibration. Scand $\mathcal{F}$ Work Environ Health 1989;15:339-44.

9 Juntunen J, Matikainen E, Seppäläinen AM, Laine A Peripheral neuropathy and vibration syndrome. Int Arch Occup Environ Health 1983;4:17-24.

10 Sukharevskaia TM, Loseva MI, Bolotnova TV, Shpagina LA, Pakhomova AM. Cell-membrane aspects of the pathogenesis of hypoxia in vibration disease induced by local vibration. Ter Arkh 1991;63:84-8.

11 Hachulla E, Devulder B. Calcium antagonists and Raynaud's phenomenon. Therapie 1993;48:707-11.

12 Pelmear PL, Taylor W. Hand-arm vibration syndrome. $\mathcal{f}$ Fam Pract 1994;38:180-5.

13 Takimoto I, Fujibayashi K. Effect of flunarizine on experimentally induced facial nerve injury. Acta Otolaryngol (Stockh) 1988;446:152-6.

14 Regan RF, Choi DW. The effect of NMDA, AMPA/kaynate and calcium channel antagonists on traumatic cortical neuronal injury in culture. Brain Res 1994;633. cal neu $236-42$.

15 Rusovan A, Kanje M. D600, a $\mathrm{Ca}^{2+}$ antagonist, prevents stimulation of nerve regeneration by magnetic fields. Neuroreport 1992;3:813-4

16 Kanje M, Lundborg G, Edström A. A new method for studies of the effects of locally applied drugs on peripheral nerve regeneration in vivo. Brain Res $1988 ; 439$ 116-21.

17 Kerns JM, Danielsen N, Holmquist B, Kanje M, Lundborg $\mathrm{G}$. The influence of predegeneration on regeneration through peripheral nerve grafts in the rat. Exp Neurol 1993;122:28-36.

18 Dahlin LB, Miyauchi A, Danielsen N. Thomsen P, Kanje $M$. Stimulation of nerve regeneration by macrophages in granulation tissue. Rest Neurol Neurosci 1996;9:141-9.

19 Rusovan A, Kanje M. Stimulation of regeneration of the rat sciatic nerve by $50 \mathrm{~Hz}$ sinusoidal magnetic fields. Exp sciatic nerve by $50 \mathrm{~Hz}$

20 Siegel S. Non-parametric statistics: for the behavioral sciences. Tokyo: McGraw-Hill Kogakusha, 1956.

21 Mattson MP, Kater SB. Calcium regulation of neurite elongation and growth cone motility. $\mathcal{F}$ Neurosci $1987 ; 7$ $4034-43$.

22 Tsien RW, Lipscombe D, Madison DV, They KR, Fox AP. Multiple types of neuronal calcium channels and their selective modulation. TINS 1988;11:431-8.

23 Strömberg $T$, Lundborg $G$, Holmquist $B$, Dahlin $L B$. Impaired regeneration in rat sciatic nerves exposed to short-term vibration. $\mathcal{F}$ Hand Surg [Br] 1996;21:776-9.

24 van der Zee, Schuurman T, Traber J, Gispen WH. Oral administration of nimodipine accelerates functional recovery following peripheral nerve damage in the rat. recovery following peripheral

25 Angelov DN, Neiss WF, Streppel M, Andermahr J, Mader $\mathrm{K}$, Stennert E. Nimodipine accelerates axonal sprouting after surgical repair of rat facial nerve. $\mathcal{F}$ Neurosci 1996 16:1041-9.

26 Schanne FA, Kane AB, Young EE, Farber JL. Calciumdependence of toxic cell death: a final common pathway. Science 1979;206:700-2. 